\section{Blends and Composites}

The later stages of the conference dealt with distinct two phase materials with a number of talks on rubbertoughened as well as fibrous systems. C.B. Bucknall (Cranfield) talked on the principles and consequences of varying the size of the rubber particles on the fracture properties of toughened nylon. He found that at low strain rates, the size of the rubber particles did not influence the toughness of the polymer whereas at high rates of strain, matrices with larger particles tended to offer improved toughness. He also discussed the feasibility of adding thermoplastics to epoxy resins in order to enhance their fracture toughness. It was stated that the shortterm toughness of an epoxy can be increased by a factor of three by adding fifteen percent of poly-ether-imide.

Local activities were presented by W.J. Cantwell and A.C. Roulin-Moloney, who reported on the considerable experience of the Lausanne Laboratory in dealing with the fractographic analyses of pure and loaded resins in a wide range of strain rates and temperatures (see also Fractography and Failure Mechanisms of Polymers and Composites, ed. A.C. Roulin-Moloney (Elsevier Applied Science, Barking) 1989.

Two quite surprising conclusions were drawn from this multitude of data:

a) The total energy available within a specimen determines the fracture surface roughness;

b) A crack clearly needs some time and distance - in order to accelerate up to the limiting crack speed.

One of the most enlightening talks was given by R.J. Young (Manchester) on the subject of the application of Raman spectroscopy to the analysis of micro-deformation in single fibres. Here, it was shown that the technique can be used to determine the magnitude of shrinkage stresses in fibre-reinforced composite materials. This is of particular importance since thermal stresses are often a cause of the premature failure of laminated composites. Young and his colleagues were the first to determine experimentally the size of the critical transfer length in a high modulus fibre.

Another view into the future, the very promising subject of the behaviour of special three-phases composites, was treated by F.J. McGarry (Cambridge/ Mass.). The talk spanned in a short historical review the very first (and then unsuccessful) attempts of blending in the 40 s, the present role of a rubber phase in polymers, and that of rubbercoated glass and carbon fibres. Coating increases impact strengths by up to
8 -fold while diminishing only slightly (10 to $30 \%$ ) the transverse tensile strengths of the composites.

Important contributions to the conference also came from the 54 individual poster contributions. As an example, the invited paper on chain interdiffusion (M. Tirrell) was ably supported by six posters on the dynamics of entangled polymer melts, and on adhesion, knit line formation, welding and fracture of different polymers. Eight posters dealt with crazing, showing e.g. interesting computer simulations, explaining the toughening effect of rubber particles (through geometrical interaction of the particles beyond a critical filling ratio of between 6 and 17\%) or of ion-content (in sulfonated polystyrene).

The conference was a great success, attracting 180 participants from eighteen countries including the USA, Japan, Canada, Australia, Russia, and of course most European countries. It was accompanied by a well-received exhibition of relevant books from most of the pertinent polymer publishing companies featuring works on general polymer physics, chemistry, mechanics and processing as well as a special selection of books on polymer fracture.

Extended abstracts of all contributions are found in Europhysic Conference Abstracts, Vol. $12 \mathrm{~J}$ (1988).

\title{
ICFA Plots a New Course
}

\author{
W.O. Lock, CERN
}

The initial activities of ICFA, the International Committee for Future Accelerators, established in 1976 by the Particles and Fields Commission of the International Union of Pure and Applied Physics (IUPAP), revolved around the idea of a 'World Machine' [1]. However, to keep abreast of the changing world physics scene, in August 1985 its mandate was re-defined as:

- to promote international collaboration in all phases of the construction and exploitation of very high energy accelerators;

- to organize regular world-inclusive meetings to exchange information on future plans for regional facilities and to formulate advice on joint studies and uses;

- to organize workshops to study problems related to super high energy accelerator complexes and their international exploitation and to foster research and development of necessary technology.

\section{General ICFA Activities}

Following the second of the new IUPAP guidelines, ICFA organized a second "Future Perspectives in High Energy Physics" Seminar at the Brookhaven National Laboratory, USA, in October 1987. It attracted a wide attendance not only from the major high energy physics laboratories in eastern and western Europe, the USA, USSR and Japan but also from Argentina, Australia, Brazil, Canada, China, Mexico, Pakistan and South Korea [2]. The next
Seminar in the series will be held in the Soviet Union at the Serpukhov Institute of High Energy Physics in the spring or autumn of 1990. Although such meetings are clearly useful, especially with many developing countries becoming increasingly involved in different aspects of high energy and accelerator physics, they can do little more than serve as a forum for exchanging information and ideas. The active role of ICFA today is best mirrored in the work of the four specialist Panels, established after the 1984 Seminar [1].

\section{Panel on Future Instrumentation Inno- vation and Development}

The aims of this Panel are to create new channels of communication and to stimulate the involvement of all regions of the world in experimental high energy physics. In pursuance of these, the Panel has organized the ICFA Instrumentation School, the ICFA Instrumentation Bulletin, and the ICFA Review of Detector Properties.

The Instrumentation School teaches to Ph.D. students or young Ph.D.s the physics and technology of particle detectors and the experimental requirements of new and planned accelerator facilities. Hands-on laboratory exercises constitute an important part of the School. The aim is to have about equal participation from industrialized and developing countries. The first School was held at the International Centre for Theoretical Physics (ICTP) in Trieste, Italy in June 1987 and was attended by 
74 students, 45 from developing countries [3]. A second School is planned, also at ICTP, for June 1989 and might be repeated in Brazil in 1990 primarily for students from Latin America, but also for the rest of the world.

With initial financial assistance from the University of Siegen, the DESY Laboratory and the German Ministry for Research and Development, four issues of the ICFA Instrumentation Bulletin have been published since March 1986. ICFA Review of Detector Properties will appear as a special issue of Nuclear Instruments and Methods (North-Holland) and as a small booklet, the instrumentation analogue of Review of Particle Properties.

\section{Beam Dynamics Panel}

This Panel has initiated a Beam Dynamics Newsletter intended as a channel for describing planned work and unsolved problems. The Newsletter is printed by the DESY Laboratory and to date three issues have been published.

The Panel has also organized two Workshops on specialized topics while a third on the topic of Beam-Beam Effects in Circular Colliders is planned for summer 1989 in Novosibirsk. A proposal to hold a Beam Dynamics School at ICTP in Trieste has been approved. The topic will be Beam Dynamics and Engineering of Synchrotron Radiation Sources.

\section{Superconductivity and Cryogenics}

The first activity of this Panel was to organize a Workshop on Superconducting Magnets and Cryogenics at the US Brookhaven National Laboratory in May 1986. As well as attracting participants from all over the world, $40 \%$ of the attendance came from industry, reflecting the growing industrial involvement in new or planned large-scale accelerator facilities [4]. More recently the Panel has prepared a draft paper "ICFA Standard for Superconducting Wire and Cable for Accelerator Magnets" whose wide circulation will include major industrial firms with a view to reaching general agreement at the meeting of the Panel in Japan in August 1989.

\section{New Accelerator Schemes and Techno- logy}

For a number of reasons it was difficult for this Panel to initiate its programme of activity and the first Workshop on "The Physics of Linear Colliders" was held only in June of last year in Italy. A Workshop on "10 TeV electronpositron collider design" is tentatively planned for 1990. Members of the Panel plan to visit laboratories in the USSR in the Autumn of 1989.

\section{Summary}

At the end of a critical review at the 1987 Seminar of ICFA's activities it was concluded that they were unique in that they involve not only the Soviet Union but also many developing countries in Latin America and in Asia.

The next meeting of ICFA will take place in Beijing in August 1989 at the invitation of the Chinese Academy of Sciences and of the Institute of High Energy Physics, Beijing. It will be associated with a meeting of the Instrumentation Panel, a Symposium on "The Status of the Main Accelerators and Detectors in the World" and is provisionally entitled "BEPC-ICFA Workshop on Frontier Detectors for Particle Physics" intended mainly for participants from China.

\section{REFERENCES}

[1] Lock W.O., Europhys. News 16 (1985) 6 , 13.

[2] Summary in CERN Courier 27 (1987) 10, 1; Proceedings BNL 52114 (1988).

[3] Proceedings available as Instrumentation in Elementary Particle Physics, eds. E.W. Fabjan and J. Pilcher (World Sci. Publishers, Singapore) 1988.

[4] Proceedings available as BNL 5206.

\section{MAILING LIST}

To be placed on the mailing list of the newsletters, apply for

Instrumentation to: Editorial Office

University of Siegen, Physics Department Adolf-Reichweinstr., D-5900 Siegen

Beam dynamics to: A. Piwinski,

DESY, Notkestr. 85

D-2000 Hamburg 52

\section{NETHERLANDS' ENERGY RESEARCH FOUNDATION (ECN)}

The Foundation ECN is the central institute in The Netherlands for strategic research and development in the area of energy generation for government and industry. Its programmes are directed towards advanced techniques of energy conversion and cover aspects of safety, environment and waste handling.

The research programme of ECN includes a wide area of materials research. ECN has approximately 900 employees and is located on the coast about $60 \mathrm{~km}$ north of Amsterdam.

The Solid State Physics group in the Department of Physics carries out programmes on neutron scattering and positron annihilation. As a part of the national programme on high- $T_{c}$ superconductivity, the group studies the electronic structure of superconductors with the aid of the positron annihilation angular correlation technique.

Applications are invited for the position of

\section{POSTDOCTORAL RESEARCH FELLOW $(\mathrm{m} / \mathrm{f})$ in electronic band structure computation}

The position is for a period of two years. The successful candidate, who must have experience in the field of band structure computation, will work on the electronic structure of ceramic superconducting materials with high $T_{c}$. He is expected to perform his research in close collaboration with the group Electronic Structure of Materials of the Catholic University of Nijmegen and the Positron Annihilation Project at ECN. To that end he will be stationed at Nijmegen during the first year of his appointment. The salary will be in the range of Dfl. 4609.- to Dfl. 5118.- per month.

Applications, together with a curriculum vitae and a list of publications, should be sent to the Personnel Bureau of ECN, P.O. Box 1 , 1755 ZG Petten. The Netherlands (telefax + 31224644 80), reference Fys-69/545.

Deadline of application: 15 May, 1989.

For further information, please contact :

Dr. P.E. Mijnarends, ECN, 1755 ZG Petten,

The Netherlands, phone + 3122464528 .

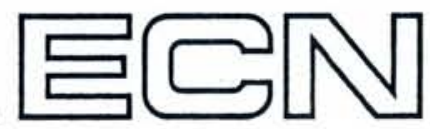

